\title{
Assessment of Curbside Roadway Level of Service of The Bandaranayke International Airport - Sri Lanka: A Comparison of The Analysis Tools in ACRP 40
}

\author{
Hadunneththi R. Pasindu, Kaushan W. Devasurendra, and Pathiraja A. S. Udayanga
}

\begin{abstract}
This study utilizes the most recent data set available on Bandaranaike International Airport Curbside Operations, collected in 2012, in assessing the curbside roadway level of service. The level of service of both the departure and arrival curbside roadways are evaluated using the guidelines presented in the ACRP 40 report on Airport curbside and Terminal Area Roadway Operations. This study compares the two evaluation procedures suggested in ACRP 40 where only one vehicle type is assumed and where the actual vehicle configuration is taken in to account and the factors affecting the differences are discussed. Upon unavailability of an exact method/function to obtain the factor to derive design stall requirement from the calculated stall requirement, an appropriate function was developed to predict required values in the calculation. The LOS of the BIA for the given data set was derived as $E$ for both arrival and departure curbs which is different from the previous study done by Sameera using the same data set. Consideration of the vehicle configuration found to have affected the difference of the outcome mainly. The through lane level of service did not affect the outcome.
\end{abstract}

Index Terms - ACRP 40 guidelines, airport curbside roadway, curbside level of service.

\section{INTRODUCTION}

A irports have become a competitive market, especially in North America and Europe, with a total passenger movement of 7.2 billion worldwide in 2015 and keep growing [1,2]. Although airports are not subjected to direct competition at some instances $[3,17]$, such as countries with comparatively less air passenger movements, the quality of service provided by such airports establishes the first impression of the country or city for passengers from outside and this perception counts for the economy of the city or

H.R. Pasindu is with the School of Highway, Chang'an University, 710064, Xi'an, China (e-mail: udayanga.sajith@yahoo.com)

K.W. Devasurendra is with the Department of Civil Engineering, Schulich School of Engineering, University of Calgary, Canada country specially with tourism industry. Therefore, evaluating performance and level of service of airports have become of utmost importance to the airlines and airport operators [4]. Therefore, a lot of research have been carried out over the world in view of evaluating level of service and performance of airports and measures to improve them. $[5,6,7,8,9]$

\subsection{Curbside level of service}

The primary function of an airport terminal is to facilitate the passenger transport in between ground transportation system and air transportation system. The main function of the curbside roadway is to facilitate the passenger transfers between the ground transportation system and terminal building.

As the air passenger traffic continues to increase, the congestion of the airport curbside roadways has become a major issue across many parts of the world [10]. Despite the increasing airport passenger movements, the curbside roadway capacity is limited by the length of available curbside lane which depends on the length of the terminal building and passenger walking distances. These issues have motivated several research attempts on curbside roadway level of service.

Level of service is a quality measure evaluating the perception of user depending on several key factors. Mandle (1982) adopts a curbside level of service criteria ranging from depending on effective curbside utilization out of the actual curb frontage where double or triple parked area is used to derive the effective curb length [11]. Siddiqui suggested a criterion of assessing level of service ranging from A to E depending on utility equations developed by him taking the 'time' and 'passenger walking distance into account' [5,12] suggested a mechanism to assess level of service of airport curbside with more attention to user perception. He proposed three ranges of level of service that took the effective curb utilization, passenger walking distance and waiting time in to account.

\subsection{Curbside roadway of BIA}

P.A.S. Udayanga is with the Department of Civil \& Environmental Engineering, Saitama University, Japan. 
Bandaranaike International Airport (also known as Colombo International Airport, IATA: CMB) is one of two international airports in Sri Lanka located $31 \mathrm{~km}$ north of Colombo City Center and currently serving a 9.5 million annual passenger movement.

The departure curbside roadway is located after the airport access roadway and before the arrival curbside roadway. The weaving roadway section is in between the departure and arrival curbsides. Departure curbside road way consist of two porches, each with two lanes. Inner porch mainly accommodates the departure curbside access vehicles and the outer porch two lanes mainly accommodates through traffic. The survey observations by Galagedara (2013) describes that hardly any public vehicles stop at the departure curbside to unload passengers apart from the heavy vehicles needing to access duty free shops $[7,8]$. Therefore, only the inner porch of the departure curbside will be considered in the curbside utilization calculations. The arrival curbside roadway consists of two porches with inner porch having two lanes and outer porch having three lanes. Same as in the departure curbside, the inner porch two lanes are serving the public to pick up air passengers and the inner lane of outer porch is mainly occupied by airport operated taxi service while the remaining two lanes of the outer porch serves mainly the through and circulating traffic. Therefore, during the analysis of curb side utilization, only the inner porch of the arrival curbside roadway will be considered. Both arrival and departure curbsides are equal in length and composition.

The curbside roadway consists of 4 lanes with two porches and with an adjacent lane for circulating traffic that is used by bypass traffic as well where all the five lanes are in the same direction. This lane is separated from a median and again gets open to the weaving section and again gets combined with the outer porch lanes of the arrival curbside making the number of lanes in the outer porch of the arrival curbside being three lanes which accounts to a total of 5 lanes as compared to the total of 4 lanes in the departure curbside.

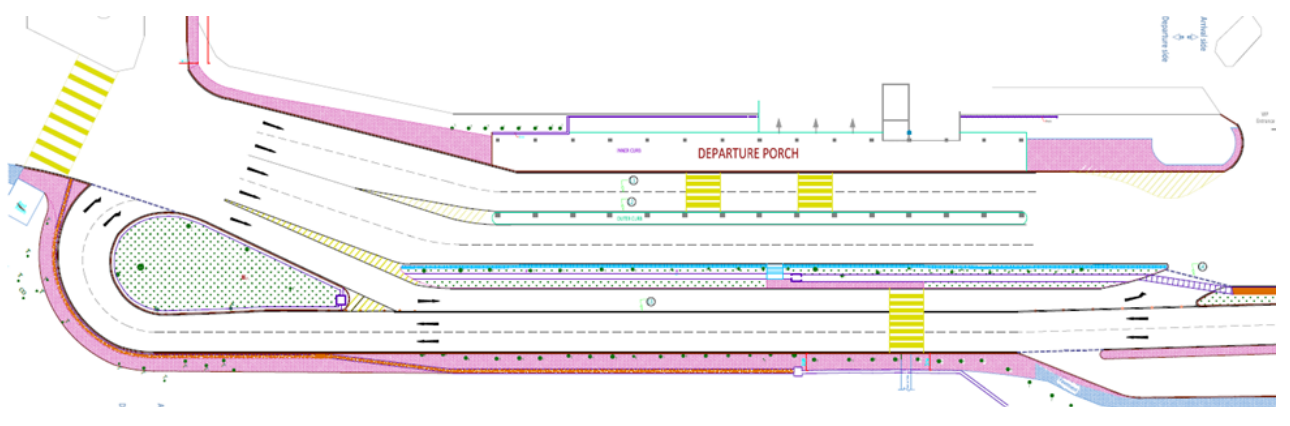

Fig.1 - Departure Curbside Roadway Layout of the Bandaranaike International Airport of Sri Lanka

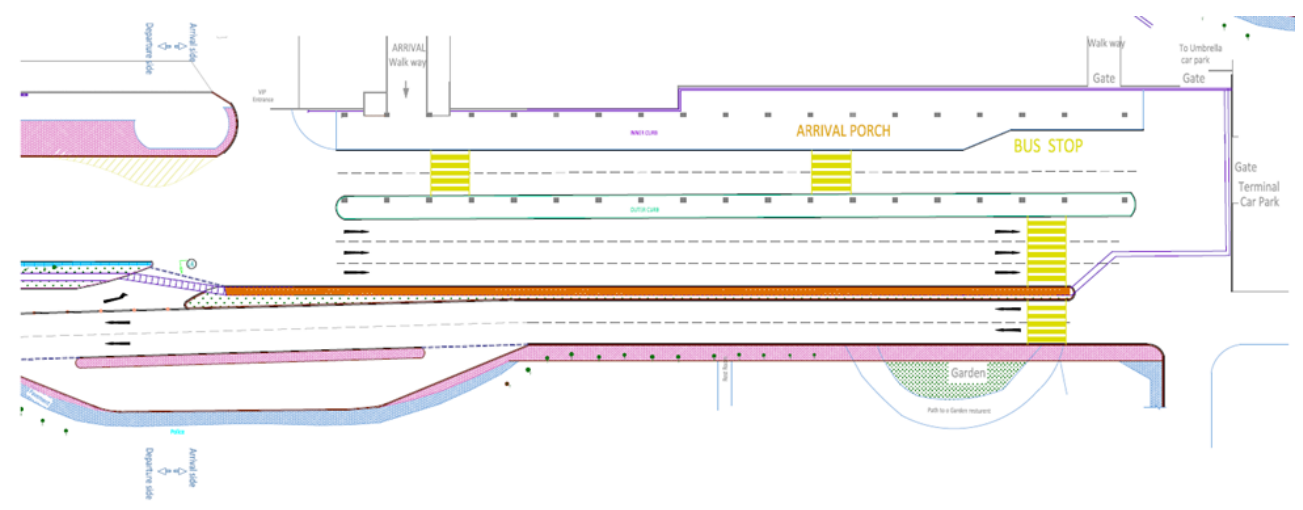

Fig. 2 - Arrival Curbside Roadway Layout of the Bandaranaike International Airport of Sri Lanka.

\section{OBJECTIVE}

Despite the amount of research had been conducted on the Level of Service (LOS) of the airports, there is no standard method exists on international level (Correia \& Wirasinghe,
2004). Considering the importance of assessing level of service of existing airport facilities, the Airport Cooperative Research Program (ACRP), presented a guideline to estimate airport roadway requirements and suggested performance measures to assess the roadway performance through their report; 'ACRP 
40: Airport Curbside and Terminal Area Roadway Operations' in 2010 [9].

An assessment of the curbside roadway level of service of the Bandaranaike International Airport (BIA) of Sri Lanka has been carried out. The study follows the guidelines presented by the ACRP 40. However, the level of service has only being assessed based on the curbside utilization factor and assuming only one vehicle type. According to the guidelines presented in the ACRP 40, which further suggests, a) taking the through traffic of the curbside in to account in the normal calculation and $b)$ to consider the actual vehicle configuration if more accuracy is needed and suggests another procedure to be followed in such an instance. Galagedara (2013), in their study, follows the normal procedure and assumes a single stall length for all the vehicles where as in actual situation there are mainly three types of vehicles using the departure and arrival curbsides.

Therefore, the objective of this study is to assess the curbside roadway level of service of the BIA of Sri Lanka following the more comprehensive procedure presented in the ACRP 40 by taking the actual vehicle configuration and respective stall lengths in to account and to compare the outcomes arrived by two methods using the findings of particular study. The outcome will provide the airport authorities a better understanding of how well the airport curbside infrastructure is

consumed at the curbside, Type of the vehicles stopping at the curbside, Effective curbside lengths of arrival and departure curbside. The analysis presented in this study assume that total peak hour traffic served by the departure curbside roadway section is approximately equal to the access roadway peak hour traffic (591 veh/hr) and total peak hour traffic served by the arrival curbside roadway is approximately equal to the weaving section peak hour traffic (990 veh/hr).

\section{Methodology}

ACRP 40 presents a quick estimation method to assess the capacity and level of service of the airport curbside roadway using the Table 5-2 using curbside demand and traffic volumes. There are two main steps in the assessment of the level of service of the curbside roadway where the first step being the assessment of the curbside utilization factor (i.e.: the ratio of curbside demand and curbside capacity) and the second step being the assessment of the maximum throughput rate of the curbside roadway. The level of service of the curbside roadway is then taken as the worst out of the two measures.

\subsection{Assessment of curbside utilization factor}

Curbside Utilization Factor (hereafter referred to as CUF) is the ratio of curbside demand and the capacity. The curbside demand, which is also referred to as the curbside lane requirement can be assessed following the procedure presented in ACRP 40. Following equation introduced by the ACRP 40 can be used to assess the curbside lane requirement under the assumption of single class of vehicles where it uses the same stall length for all the vehicles.

$$
\mathrm{R}_{\mathrm{a}}=V^{*} D_{i} / 60 * L
$$

performing and an insight of the accuracy of possible outcomes.

\section{DATA SET}

It is not often where data collections are being carried out with the view of assessing curbside LOS. As a result, comparatively a little amount of research has been conducted with related to airport curbside level of service despite the recent initiatives to expand the terminal building of the Bandaranaike International Airport (BIA) of Sri Lanka [13] of which the data are not available for public and research purposes.

Therefore, this study utilizes the data set collected by Galagedara (2013) and Udayanga (2015) to evaluate the BIA curbside roadway LOS according to the more comprehensive method suggested by ACRP 40 where the actual vehicle configuration should be taken in to account. Some of the data required for the analysis presented in this study and missing in the data set used in this study was assumed using the available data and described in detail in the relevant sections.

The data used in this study comprises of; Peak hour volumes of vehicles stopping at the departure and arrival curbsides by using the access road and weaving section, dwell time each vehicle

Where; $R_{a}, V, D_{i}, L$ are the average curbside length required, the hourly volume of vehicles stopping at a curbside area, the average vehicle dwell time (in minutes), the average vehicle stall length respectively.

A separate procedure to be followed is presented when the vehicle configuration consists of more than one vehicle type in Table 5-3. This procedure consists of estimating the number of vehicle stalls required by each vehicle type during the corresponding peak hour at each departure and arrival curbside roadways depending on the respective dwell times and percentages of each vehicle type during the peak hour.

It is then required to determine the average vehicle stall lengths for each type of vehicles and it is suggested to use the de facto values given in the Table 5-3 of the ACRP 40. While the arrival curbside vehicle configuration consists mainly the cars and vans (dual purpose vehicles), the departure curbside vehicle configuration consists of a vehicle type known as three wheelers (mostly popular as the tuk tuk or auto rickshaw) apart from the regular cars and vans. Although the Table 5-3 suggests vehicle stall lengths for cars and vans, it does not give a vehicle stall length value for three wheelers. The vehicle stall length is longer than the actual length of the vehicle by a certain percentage. A comparison of actual dimensions of cars [14] and vans [15] and the vehicle stall lengths is presented in the following table.

The percentage increase in the stall length for the threewheeler than the actual length can be assumed as the lower percentage out of the above two percentages utilized in the ACRP 40 since three wheelers are well known for their easy manoeuvrability and hence a shorter distance is enough for the required ingress and egress manoeuvres. Accordingly, the actual length of a three-wheeler can be taken as $2.7 \mathrm{~m} \mathrm{[18]} \mathrm{and}$ hence the stall length of a three-wheeler can be calculated as; $2.7 * 130 \%=3.51 \mathrm{~m}$. 
TABLE I

Percentage InCREASe In THE Vehicle Stall Lengths than ACtual VEHICLE LENGTH

\begin{tabular}{cccc}
\hline $\begin{array}{c}\text { Vehicle } \\
\text { type }\end{array}$ & $\begin{array}{c}\text { Actual/ } \\
\text { nominal } \\
\text { length }\end{array}$ & $\begin{array}{c}\text { Stall } \\
\text { length }\end{array}$ & $\begin{array}{c}\text { Percentage } \\
\text { increase in stall } \\
\text { length }\end{array}$ \\
\hline Car & $4.86 \mathrm{~m}$ & $7.62 \mathrm{~m}$ & $156 \%$ \\
\hline Van & $7.0 \mathrm{~m}$ & $9.14 \mathrm{~m}$ & $130 \%$ \\
\hline
\end{tabular}

Mostly the TWs transport only one air passenger from or to the curbside due to the space limitation and maximum is 2 . Therefore, it can be fairly assumed that a TW serves 1.5 air passengers on an average to be in the safe side where the actual number will be closer to 1 . From the graph of number of air passenger vs vehicle dwell time depending on the survey observations, for TWs, it can be assumed to consume an average dwell time of 2.635 seconds for 1.5 passengers during the peak hour. This value is taken as the average dwell time for TWs in the LOS calculation.

The next step involves with deriving the number of required design stalls by multiplying the number of required curbside stalls by a factor (F) which is "ranging from 3.0 for requirements less than 5 curbside stalls to 1.2 for curbside stall requirements of 100 or more" [9] and follows a Poisson distribution of which no parameters were presented. That is, for curbside stall requirements less than 5 , the value of the factor is 3 and a constant and for curbside stall requirements higher than or equal to 100 , the value of the factor is 1.2 and a constant. For curbside stall requirements between 5 and 100, this factor is a variable and said to follow a Poisson distribution.

However, for curbside stall requirements between 5 and 100 , there is no method presented and it is unable to find out the value of this factor. Table 5-3 presents a sample calculation from data gathered from several airports and consist of few data points where the stall requirements lie between 5 and 100 . During the analysis, it is found that the curbside stall requirements for both departure and arrival curbside for each vehicle type lies between 5 and 100 and need a method to figure out a proper value for the factor $F$. The few data points that lies between 5 and 100 curbside stall requirements together with few data points beyond the limits of 5 and 100 are tabled against respective $\mathrm{F}$ values as below.

A closer look at the data in the table make it evident that the relationship in between the data points regarding $\mathrm{F}$ value is not linear and hence linear interpolation with estimating new values is not possible. It was then attempted to fit a potential curve with these data values where it is possible to obtain a curve with a sufficient fit so that the new values can be estimated with sufficient accuracy. The best fitting curve for the values presented in data could be found through a 4PL (Four Parameter Logistic Regression curve) symmetrical sigmoidal curve with an $\mathrm{R}^{2}$ value of 0.9987 . This model fit was obtained using the online curve fitting tool named MyCurveFit. The obtained fitted curve is illustrated in Fig. 3.

TABLE II

REQUiRed Stall LeNGTHS VS CALCUlated F VALUES From ACRP 40

\begin{tabular}{ccccccccc}
\hline Required Vehicle Stalls & 3 & 5 & 18 & 30 & 31 & 50 & 100 & 110 \\
\hline F value & 3 & 3 & 1.38 & 1.3 & 1.29 & 1.24 & 1.2 & 1.2 \\
\hline
\end{tabular}

$$
\begin{gathered}
y=1.229878+(3.014098-1.229878) /(1+(x / \\
11.38071)^{5.095572}(3)
\end{gathered}
$$

The format of the four-parameter logistic regression model can be presented as follows.

$$
Y=d+\frac{a-d}{1+\left(\frac{x}{c}\right)^{b}}
$$

Where, $\mathrm{Y}=\mathrm{F}$ value; $\mathrm{X}=$ Number of Stalls and $\mathrm{a}, \mathrm{b}, \mathrm{c}$ and $\mathrm{d}$ are model specific parameters. The model fitting parameters for the fitted model are; $\mathrm{R}^{2}=0.9987, \mathrm{R}^{2}=0.997-\left(\right.$ the $\mathrm{R}^{2}$ value adjusted downward to compensate for over fitting), $\mathrm{P}=0.00011$ - (Significance of the model as a probability), $\mathrm{SE}=0.0429$ (Standard error - root mean square of the residuals).

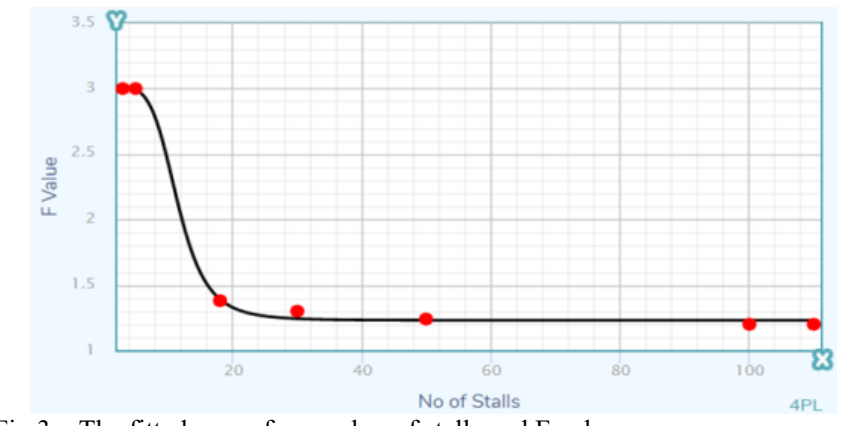

Fig. 3 - The fitted curve for number of stalls and F value

The equation of the obtained model is presented below.
Where, $\mathrm{a}=3.014098, \mathrm{~b}=5.0955, \mathrm{c}=11.3807$, $\mathrm{d}=1.2298$

This model could predict the values in the table with a better accuracy. Therefore, this model will be used in the calculation of the required $\mathrm{F}$ values in the Analysis section. Upon deriving the required $F$ values for the obtained curbside stall requirements for each type of vehicle, the respective

design stall requirements are derived using the obtained $\mathrm{F}$ values as described in the earlier step. These values are then rounded up to the immediate whole number in the upper bound. The required design stall lengths for each vehicle type is then derived by multiplying the number of required design stalls for each vehicle type by their respective vehicle stall lengths as given in the Table 5-3 in ACRP 40 for cars and vans and as derived earlier for three-wheelers.

As the next step, the obtained respective design stall lengths for each vehicle type is added up to come up with the required total length of curbside lane. The ratio of this value to the existing effective curbside length is known as the CUF, that is required to assess the level of service of the curbside lane. With 
reference to the obtained CUF value, considering whether double parking is allowed or not, by rounding up the CUF value to the next immediately available value given in the Table 5-2 in ACRP 40, the respective level of service is obtained.

\subsection{Through lane requirement}

With reference to the obtained level of service of the curbside lane, depending on the number of curbside lanes available and whether double or triple parking is allowed or not, the respective maximum service flow rate (Capacity) can be obtained for the concerned curbside (Departure or Arrival). The corresponding volume to capacity ratio $(\mathrm{V} / \mathrm{C})$ is then obtained and rounded up to the next nearest value on the Table 5-3 and the corresponding level of service is noted.

4.3 Factors affecting the dwell time and hence the curbside level of service

The lowest level of service obtained is taken as the overall level of service of the curbside roadway. From the equation for assessing the curbside lane requirement for single type of vehicle presented earlier shows that, higher the dwell time, higher the curbside requirement. Higher the curbside requirement, higher the CUF since it is given by the ratio of curbside lane requirement to available effective curbside lane length which is a constant for a given terminal building. Therefore, higher the effect of each factor on dwell time, higher the effect of respective factor on the level of service and the effect is negative since higher CUFs are related to lower levels of service. If the coefficient of the independent variable of a single independent variable regression equation derived with a sufficient fit is high, the effect of that factor (in this case independent variable) towards the dependent variable (in this case the dwell time) is high.

\section{ANALYSIS AND RESULTS}

As explained in the introduction, the inner porch consists curbside lane for vehicles stopping at the curbside and the adjacent maneuvering lane for the vehicles to ingress in to the curbside lane and egress out of the curbside lane. The two lanes in the outer porch is mainly used by through traffic.

\subsection{Departure curbside roadway}

The peak hour traffic has been observed during 21:00 to 22:00 hours and the volume was noted as $296 \mathrm{veh} / \mathrm{hr}$. Several key measures obtained from the data set and calculations described earlier and relevant to the assessment of the level of service of the BIA departure curbside roadway are as follows in the Table III;

TABLE III

PARAMETER FOR LOS AT DEPARTURE CURBSIDE

\begin{tabular}{llll}
\hline \multicolumn{1}{c}{ Data for LOS } & \multicolumn{1}{c}{ Cars } & \multicolumn{1}{c}{ Vans } & \multicolumn{1}{c}{ TWs } \\
\hline $\begin{array}{l}\text { Vehicle composition during } \\
\text { peak hour }\end{array}$ & $41 \%$ & $36 \%$ & $23 \%$ \\
\hline $\begin{array}{l}\text { Dwell times of each vehicle } \\
\text { type }\end{array}$ & $\begin{array}{l}2.9 \\
\text { minutes }\end{array}$ & $\begin{array}{l}3.09 \\
\text { minutes }\end{array}$ & $\begin{array}{l}2.635 \\
\text { minutes }\end{array}$ \\
\hline $\begin{array}{l}\text { Vehicle stall lengths of each } \\
\text { vehicle type }\end{array}$ & $7.62 \mathrm{~m}$ & $9.14 \mathrm{~m}$ & $3.51 \mathrm{~m}$ \\
\hline $\begin{array}{l}\text { Number of vehicles served by the curbside lane during peak hour }=296 \\
\text { veh }\end{array}$ & & \\
\hline $\begin{array}{l}\text { Available effective curbside length is 140m, while peak hour trough } \\
\text { volume is 591 veh/hr. }\end{array}$
\end{tabular}

5.2 Curbside utilization factor of the departure curbside CUF is defined as the ratio of curbside demand \& curbside capacity. Parameters were obtain as shown in the Table IV as follows.

TABLE IV

PARAMETER FOR CUF

\begin{tabular}{cccc}
\hline Parameters for CUF & Cars & Vans & TWs \\
\hline Volume of vehicles during peak hour & 121.36 cars & 106.56 vans & 68.08 TWs \\
\hline The required number of vehicle stalls & 5.86 stalls & 5.49 stalls & 2.99 stalls \\
\hline Corresponding F values & 2.955 & 2.971 & 3.000 \\
\hline Design stall requirements & 18 cars & 17 vans & 9 TWs \\
\hline Required design stall length & $137.16 \mathrm{~m}$ & $155.38 \mathrm{~m}$ & $31.59 \mathrm{~m}$ \\
\hline
\end{tabular}

Therefore, the total design curbside lane length $(184.13 \mathrm{~m})$ required is calculated by adding up the required design stall lengths for cars, vans and TWs. Effective curbside length available is $140 \mathrm{~m}$.

Therefore, CUF $=$ required length of curbside lane / available effective curbside length

$$
=184.13 / 140=1.315 \rightarrow \mathrm{CUF}=1.315
$$

Since the double parking is prohibited in the departure curbside area, the corresponding next nearest CUF value given in the Table 5-2 is 1.35 and corresponds to the level of service E. Therefore, the Level of Service of the Departure Curbside Lane $=$ LOS E

\subsection{Through lane requirement for departure curbside}

With reference to the Table 5-2 of ACRP 40, the corresponding maximum flow rate for a 4-lane curbside roadway where the double parking is prohibited is $2,600 \mathrm{veh} / \mathrm{hr}$. Therefore, the volume/ capacity ratio of the curbside roadway is 0.227

With reference to the Table 5-2 of ACRP 40, the corresponding level of service for a v/c ratio of 0.227 is LOS A. Therefore, although the level of service of the departure curbside through lane is high (LOS A), the Level of Service of the Departure Curbside Lane is low (LOS E). Level of service of the departure curbside roadway is taken as the worst result. Therefore, the Level of Service of the Departure Curbside Roadway of the BIA of Sri Lanka in 2012 has been LOS E. 


\subsection{Arrival curbside roadway}

Arrival curbside roadway consist of two porches where the inner porch has two lanes (curbside lane and maneuvering lane) and outer porch has 3 lanes. As described under the heading Introduction, it is legitimate to assume that only the inner porch is serving the public. The inner lane of the outer porch is mainly utilized by BIA operated taxi service vehicles and the other two lanes are serving the through traffic.

Several key measures obtained from the data set and calculations described earlier and relevant to the assessment of the level of service of the BIA arrival curbside roadway are as follows in the Table V;

TABLE V

PARAMETERS FOR ARRIVAL CURBSIDE LOS

\begin{tabular}{llll}
\hline $\begin{array}{l}\text { Parameters for arrival } \\
\text { curbside LOS }\end{array}$ & Cars & Vans & Busses \\
\hline $\begin{array}{l}\text { Vehicle composition during } \\
\text { peak hour }\end{array}$ & $42 \%$ & $57 \%$ & $1 \%$ \\
\hline $\begin{array}{l}\text { Dwell times of each vehicle } \\
\text { type }\end{array}$ & $\begin{array}{l}1.55 \\
\text { minutes }\end{array}$ & $\begin{array}{l}2.33 \\
\text { minutes }\end{array}$ & N/A \\
\hline $\begin{array}{l}\text { Vehicle stall lengths of each } \\
\text { vehicle type }\end{array}$ & $7.62 \mathrm{~m}$ & $9.14 \mathrm{~m}$ & N/A \\
\hline Number of vehicles served by the curbside lane during peak hour $=329$ \\
veh
\end{tabular}

5.5 Curbside utilization factor of the arrival curbside

Total curbside lane length required

$=83.82+191.94=275.76 \mathrm{~m}$

Effective curbside length available $=140 \mathrm{~m}$

Therefore, CUF = required length of curbside lane /

available effective curbside length

$$
=275.76 / 140=1.97 \rightarrow \mathrm{CUF}=1.97
$$

Since the double parking is allowed in the arrival curbside area, the corresponding next nearest CUF value given in the Table 52 is 2.00 and corresponds to the level of service E. Therefore, the Level of Service of the Arrival Curbside Lane $=\mathbf{L O S} \mathbf{E}$

\subsection{Through lane requirement for arrival curbside}

With reference to the Table 5-2 of ACRP 40, the corresponding maximum flow rate for a 5-lane curbside roadway where the double parking is allowed is $2,400 \mathrm{veh} / \mathrm{hr}$. The maximum vehicular traffic served by the departure curbside roadway can be taken as $990 \mathrm{veh} / \mathrm{hr}$ as explained under the heading Data Set. Therefore, the volume/capacity ratio of the curbside roadway is 0.413 . With reference to the Table 5-2 of ACRP 40, the corresponding level of service for a v/c ratio of 0.413 is LOS C. Therefore, the Level of Service of the Arrival Curbside Roadway of the BIA of Sri Lanka in 2012 has been LOS E.

\section{DISCUSSION}

Obtained results for the level of service for both departure and arrival curbsides are worse (Fig.4) than that of obtained by Galagedara(2013) and Udayanga(2015) for the same airport using the same data set. That is, the obtained Level of Service for both arrival and departure curbside roadways of BIA is LOS $\mathrm{E}$ as opposed to what was calculated in particular study as LOS C. There are three major differences in the calculation.

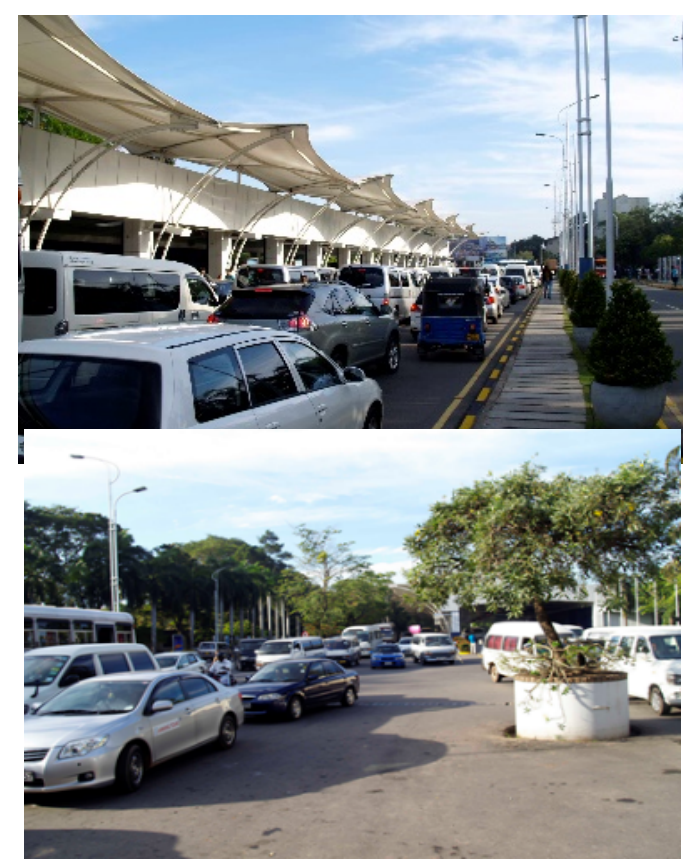

Fig. 4 - Congested Curbside at BIA

\subsection{Vehicle composition}

The first major difference in the two-analysis carried out are the vehicle composition. This study considers the vehicle composition in calculating CUF. Upon calculation of the design stall requirements which is in the format of a number with few decimals, this number needs to be converted in to a whole number because number of stalls cannot be a fraction. The process of rounding up is done towards the upper bound since, for example if the required number of stalls is 5.68, providing 5 number of stalls not going to meet the requirement and need to provide 6 number of stalls since we cannot provide fractions of stalls. Therefore, naturally, this number needs to be rounded up to the next nearest whole number.

The analysis where it concerns only one vehicle type, this conversion takes place only once and it takes several vehicle types in to account, should undergo this conversion several times where each time an additional length than the required must be added. On the other hand, the study where only one vehicle type (mostly car) is considered, utilizes only one stall length (7.62 $\mathrm{m}$ for car) and the analysis where several vehicle types are concerned, utilizes several stall lengths (one for each type of vehicle). The analysis considering several vehicle types mostly takes in to account the vans or the dual-purpose vehicles of which the stall lengths are higher than that of cars.

6.2 F Value (ratio of design stall requirements to calculated stall requirement)

The second difference in this study is the model developed to derive the corresponding $\mathrm{F}$ values. The value of $\mathrm{F}$ is high (3) closer to the stall requirements of 5 and low (1.2) closer to the requirements of greater than or equal 100 and ranging in between. This value, as the graph shows, decreases exponentially for the values closer to 5 stall requirements and 
exhibits not much difference while moving away from 5 stall requirements and reaching 100 . The analysis where only one vehicle type is considered, consist of a higher number of stall requirements and then the corresponding $\mathrm{F}$ value is closer to 1.2 where as in the study considering several vehicle types consist of smaller number of stall requirements of which the corresponding $\mathrm{F}$ values are closer to 3 (highest value of $\mathrm{F}$ ). Higher the value of $\mathrm{F}$, higher the amount of increase in the number of design stalls. Therefore, in the case of considering several vehicle types, a higher $\mathrm{F}$ value is being used several times (one time per each vehicle type) and hence output a longer curbside lane requirement.

\subsection{Through lane requirement}

The third difference is taking the through lane capacity also in to account in the calculation of the level of service of the curbside roadway. In both the arrival departure curbside calculations, the corresponding level of service of the through lane found to perform better than the respective curbside lanes (higher level of service than the curbside lane LOS). Since the Level of Service of the curbside roadway is taken as the worst of these, the main factor governing the curbside roadway level of service was found to be the level of service of the curbside lane. Taking the though lane requirement in to account has not made any major effects on the outcome.

The curbside utilization factor for both the departure arrival curbside lanes is significantly greater than 1.7 which is the acceptable value for existing facilities as recommended by the ACRP 40 [9] By 2012, for a total passenger movement of 7.079 million, the curbside level of service has been $E$ for the peak hour. The amount of passenger movement has increased up to 9.5 million from a percentage of 34 by 2016 [1]. It is essential to pay due attention to this worsening situation and take potential measures to alleviate the inconvenience the passengers have to face to cope with the expected demand increase in passenger movements in next few years to come. Tyler suggests several measures to manage the curbside congestion along with the after effects of these measure which the airport authorities can make use to get the better of a congested curbside roadway [11].

\section{CONCLUSION}

The level of service of both the departure and arrival curbside roadways of the BIA of Sri Lanka in 2012 was found to be LOS $\mathrm{E}$ as opposed to the LOS C computed using the simplified methodology proposed by ACRP 40 utilizing the same data set. It is envisaged that the new methodology provides a better representation of the traffic conditions at the curbside during peak operations. The differences in calculation procedures such as the effects of vehicle configuration, $F$ value has affected the outcome of this study significantly. Although, the consideration of curbside through lane level of service has not made any effects on the outcome, it is important to take the through lane requirement also in to account since the curbside lane operations affect the through lane operations and vice versa and hence it can influence the Level of Service of the Curbside Roadway.

\section{REFERENCES}

[1] AASL, “Annual Report 2016," Katunayaka, Colombo.: Airport and Aviation Authority, Sri Lanka, 2017.

[2] ACI, “ACI Annual World Airport Traffic Report," Montreal: Airports Council International. 2015.

[3] E. Fernandes, and R.R. Pacheco, "A Quality Approach to Airport Management," Quality and Quantity, 551-564, 2010.

[4] S. Mumayiz, "Evaluating Performance and Service Measures for the Airport Landside," Transportation Research Record, 23-30, 1991.

[5] A.R. Correia, "Evaluation of Level of Service at Airport Passenger Terminals: Individual Components," Calgary: Library and Archives Canada, 2005.

[6] A. Correia, and S. Wirasinghe, "Evaluating Level of Service at Airport Passenger Terminals: Review of Research Approaches," Transportation Research Record, 1-6, 2004.

[7] S. Galagedara, H. Pasindu, and J. Bandara, "Airport Curbside and Parking Area Operations at BIA - Analysis of User Behaviour," ENGINEER, 43-51, 2014.

[8] S. Galagedara, "Study of Airport Curbside Roadway and Parking Area Operations at Bandaranaike International Airport," Colombo: University of Moratuwa, Sri Lanka, 2013.

[9] P. Udayanga, and H. Pasindu, "Incorporating User Characteristics for Level of Service Improvements at Airport Curbside and Roadside Operations at BIA," Annual sessions of IESL, 69-75, 2015.

[10] ACRP, US, FAA, and Leigh Fisher Associates, "Airport Curbside and Terminal Area Roadway Operations," Washington DC: Transportation Research Board, 2010

[11] T. Harris, M. Nourinejad, and M. Roorda, "A Mesoscopic Simulation Model for Airport Curbside Management," Journal of Advanced Transportation, 19, 2017.

[12] P.B. Mandle, E. Whitlock, and F. LaManga, "Airport Curbside Planning and Design," Transportation Research Record, 1-6, 1982.

[13] M. Siddiqui, " A Statistical Analysis of the Factors Influencing the Level of Service of Airport Terminal Curbsides," MSc Thesis, Concordia University, Canada, 1994.

[14] S. Dias. US\$12 mn interim terminal at BIA in 18 months (2017) Retrieved from The Sunday Times: http://www.sundaytimes.lk/171105/business-times/us12-mln-interimterminal-at-bia-in-18-months-266827.html

[15] S. Antoine. 2012-2013 MIDSIZE SEDAN COMPARISON: BATTLE OF THE BEST-SELLERS (2012) Retrieved from Motor Trend: http://www.motortrend.com/cars/chevrolet/malibu/ 2013/2012-2013midsize-sedan-comparison/, 2012.

[16] Sarl. (n.d.). Van Dimensions. Retrieved from Transport Reynolds: http://www. thereddeliveryvan. co.uk/Pages/VanDimensions.aspx

[16] R. Pacheco and E. Fernandes. "Managerial efficiency of Brazilian airports," Transportation Research Part A: Policy and Practice, 667680, 2003.

[17] Specifications. Retrieved from Global Bajaj: https://www.globalbajaj.com/global/english/brands/intracity/re/re4s/specifications/. 2017. 